\title{
Article
}

\section{World Experience on COVID-19 Patients, Who Had Positive PCR for Nasal Swab and Underwent Surgical Interventions and Peritoneal Fluid Analysis for COVID- 19}

Chauhan, Muhammad Noor

Available at http://clok.uclan.ac.uk/38670/

Chauhan, Muhammad Noor (2021) World Experience on COVID-19 Patients, Who Had Positive PCR for Nasal Swab and Underwent Surgical Interventions and Peritoneal Fluid Analysis for COVID-19. Clinics of Surgery, 5 (13). ISSN 2638-1451

It is advisable to refer to the publisher's version if you intend to cite from the work.

For more information about UCLan's research in this area go to

http://www.uclan.ac.uk/researchgroups/ and search for <name of research Group>.

For information about Research generally at UCLan please go to http://www.uclan.ac.uk/research/

All outputs in CLoK are protected by Intellectual Property Rights law, including Copyright law. Copyright, IPR and Moral Rights for the works on this site are retained by the individual authors and/or other copyright owners. Terms and conditions for use of this material are defined in the policies page. 


\title{
Clinics of Surgery
}

\section{World Experience on COVID-19 Patients, Who Had Positive PCR for Nasal Swab and Underwent Surgical Interventions and Peritoneal Fluid Analysis for COVID-19}

\author{
Chauhan MN", Mohamed B and Canelo R \\ Department of Surgery Cumberland Infirmary Carlisle \& University of Central Lancashire, UK
}

\section{*Corresponding author: \\ Muhammad Noor Chauhan, \\ Department of Surgery Cumberland \\ Infirmary Carlisle \& University of \\ Central Lancashire, UK, \\ E-mail: specialistsurgeon@yahoo.co.uk}

\section{Keywords:}

COVID-19 as Surgical emergency; COVID-19 and PCR from peritoneal cavity fluid; Surgical intervention in COVID-19 patients; COVID 19 and Acute abdomen; COVID-19 in Surgical patients
Received: 15 June 2021

Accepted: 29 June 2021

Published: 05 July 2021

\author{
Copyright: \\ (C2021 Chauhan MN, et al. This is an open access article dis- \\ tributed under the terms of the Creative Commons Attribu- \\ tion License, which permits unrestricted use, distribution, and \\ build upon your work non-commercially.
}

\section{Citation:}

Chauhan MN, et al., World Experience On COVID-19 Patients Who Had Positive PCR for Nasal Swab and Underwent Surgical Interventions and Peritoneal Fluid Analysis for COVID-19. Clin Surg. 2021; 5(13): 1-5

\section{Abstract}

1.1. Aims: Aim of this literature review was to analyse the world experience on COVID-19 patients who underwent surgical intervention. Analyse the status of their peritoneal fluid and the surgical outcome in these COVID-19 patients.

1.2. Methods: Literature review of the published papers was performed over the last two years. The studies involving patients who had COVID -19 confirmed by PCR results of nasopharyngeal swabs and underwent a surgical procedure and had the peritoneal fluid samples examined to detect the presence of the COVID 19 virus.

1.3. Results: Ten papers assessing the COVID-19 in the peritoneal cavity were published, all of them were published in the year 2020. In all these studies total of 18 patients were confirmed COVID-19 on nasopharyngeal PCR and these were Assessed for the detection of the COVID-19 in the peritoneal cavity. Three patients $(3 / 18$, $16.6 \%)$ have no respiratory symptoms, fifteen $(15 / 18,83.33 \%)$ patients have respiratory symptoms. Seven patients $(7 / 18,38.8 \%)$ had COVID-19 detected in the peritoneum (Table 1), 2.dsa.

1.4. Conclusion: Patients with Respiratory symptoms are more likely to have peritoneal fluid positive for the disease. The overall mortality rate in patients with Pharyngeal PCR test +ve and who had surgical intervention is $9 / 18,50 \%$. Patients with Respiratory symptoms and positive Nasopharyngeal PCR had mortality rate of $8 / 9,88.88 \%$ among those who died in this group. It is difficult to comment on the mortality and morbidity of patients with COVID-19 in the peritoneal fluids as number of cases is small and many other variables can influence the morbidity and mortality in this group.

\section{Introduction}

The Corona virus causes respiratory infection, after 2-14 days of exposure symptoms like cough, fever, headache, myalgia and fatigue appear. Corona belongs to RNA family of viruses. Covid-19 is the new member of this family which surfaced in China in last months of 2019 [1]. During the early part of the COVID-19 pandemic new guidelines were formulated all over the world and implemented towards doctors, nurses, and healthcare workers in general, so that they can be protected from this life threatening infection while performing their duties in this COVID 19 pandemic. The surgical theatres working conditions, importantly theatre protocols have changed significantly which have financial and practical implications. The new rules were introduced in order to minimise exposure of viruses to surgeons, nurses and all other health care workers in the operation theatres. As a result of this it has resulted in the testing of patients and medical staff in the operation. The new guidelines were being quickly introduced and re updated rapidly to date by most international surgical societies, 
to give surgical staff the most reliable and consistent guide lines while performing surgical cases which have potential or proved positive for COVID-19, especially in an emergency setting. [2, 3] It's important to mention here that when first wave of COVID-19 hit UK, all the elective surgeries except cancer surgeries were suspended in most places. The health care workers were compelled to work in situations of uncertainty and high risk for more than a year and this was due to lack of relevant data about viral load in the various body compartments and fluids. [4,5] The excretion path mechanisms of COVID-19 were mostly unknown. We believe that our review of available literature on this topic of "Potential Infectiousness of Peritoneal Secretions" will give important additional information from around the world on this burning topic which is still mystery for modern world of medical science [6].

\section{Aim}

Aim of this literature review was to analyse the world experience on COVID-19 patients who underwent surgical intervention. Furthermore, to analyse the status of their peritoneal fluid and the surgical outcome in these COVID-19 patients.

\section{Methodology}

Literature review of the published papers was performed over the last two years. The studies involving patients who had COVID -19 confirmed by PCR results of nasopharyngeal swabs and underwent a surgical procedure and had the peritoneal fluid samples examined to detect the presence of the COVID 19 virus. Literature search was performed on Google and Pub Med using terms COVID19 with bowel perforation, Bowel ischemia in COVID, Peritonitis in COVID 19, COVID 19 and Acute abdomen, COVID in Surgical patients, COVID as Surgical emergency, COVID and PCR from peritoneal cavity fluid. Ten papers were identified which assessed the COVID-19 in the peritoneal cavity and which were published in the years 2020 and 2021 (Table 1).

Table 1: The published papers assessing peritoneal cavity and peritoneal fluid

\begin{tabular}{|c|c|c|c|}
\hline & $\begin{array}{l}\text { Date of } \\
\text { publication }\end{array}$ & Corresponding author & Title \\
\hline 1 & May 2020 & S. Flemming & $\begin{array}{l}\text { Abdominal fluid samples (negative for SARS-CoV-2) from a critically unwell patient with respiratory } \\
\text { COVID-19 }\end{array}$ \\
\hline 2 & May 2020 & $\begin{array}{l}\text { Isaac José Felippe Corrêa } \\
\text { Neto }\end{array}$ & Perforated acute abdomen in a patient with COVID-19: an atypical manifestation of the disease \\
\hline 3 & May2020 & Edoardo Rimini & $\begin{array}{l}\text { COVID-19 in the peritoneal fluid: does this evidence oblige to introduce new rules? Presentation of } \\
\text { a Case Report }\end{array}$ \\
\hline 4 & Jun 2020 & Barbara Seeliger & $\begin{array}{l}\text { Is the severe Acute respiratory syndrome Coronavirus } 2 \text { (SARS-CoV-2) present intraperitoneally in } \\
\text { patients with coronavirus disease } 2019 \text { (COVID-19) infection undergoing emergency operations? }\end{array}$ \\
\hline 5 & Jul 2020 & Victor C Passarelli & Detection of SARS-CoV-2 in ascitic fluid: a case of viral peritonitis? \\
\hline 6 & Jul 2020 & A. Barberis & SARS-Cov-2 in peritoneal fluid: an important finding in the Covid-19 pandemic \\
\hline 7 & Sep 2020 & Saeed Safari & Detection of SARS-CoV-2 in Abdominal and Adipose Tissues \\
\hline 8 & Sep 2020 & Federico Coccolini & SARS-CoV-2 Is Present in Peritoneal Fluid in COVID-19 Patients \\
\hline 9 & Sep 2020 & Labib S. Al-Ozaibia & Splenic Abscess: An Unusual Presentation of COVID-19? \\
\hline 10 & Sep 2020 & $\begin{array}{|ll|}\text { Margarita } & \text { Ibarra- } \\
\text { Hernandez } & \end{array}$ & $\begin{array}{l}\text { Detection of SARS-CoV-2 in peritoneal fluid from patients with kidney disease and COVID-19: } \\
\text { report of two cases }\end{array}$ \\
\hline
\end{tabular}

\section{Results}

Ten papers assessing the COVID-19 in the peritoneal cavity were published, all of them were published in the year 2020 (Table 1). Out of total 18 patients, 9 males and 9 females. Maximum age was 80 years and minimum age 30 years. Average age was 60.94 years (Table 1). In all these studies total of 18 patients were confirmed COVID-19 on nasopharyngeal PCR and these were assessed for the detection of the COVID-19 in the peritoneal cavity. Table 2. Three patients $(3 / 18,16.6 \%)$ have no respiratory symptoms, fifteen $(15 / 18,83.33 \%)$ patients has respiratory symptoms (Table
2). Seven patients $(7 / 18,38.8 \%)$ had COVID-19 detected in the peritoneum (Table 2). Rectal swab was taken in 6 patients and it was positive in 5 of them. Fifteen patients underwent different surgical interventions and two patients had peritoneal dialysis for renal disease while one patient had Paracentesis. Eight patients of them $(8 / 18,44.4 \%)$ had varying degree of GI Ischemia and underwent surgical interventions for that. Seven Patients had surgeries for other diagnosis rather than GI Ischemia while two patients underwent surgical interventions post abdominal trauma (Table 2). In our study seven patients out of eighteen (7/18, 38.8\%) had COVID-19 detected in the peritoneal cavity. All these eigh- 
teen patients were also positive for COVID-19 on nasopharyngeal swab PCR test. It's important to mention that all the patient who were positive for Covid-19 in the peritoneal cavity has respiratory symptoms as well 7/7, 100\%. Which means patients with respiratory symptoms are more likely to have peritoneal fluid positive for the disease (Table 2).

Table 2: Analysis of the patient's demography, intervention, outcome and PCR results from nasopharyngeal as well as the peritoneum

\begin{tabular}{|c|c|c|c|c|c|c|c|}
\hline & & & & & & +ve PCR & +ve PCR \\
\hline Sex & Age & Diagnosis & Intervention & Outcome & Resp symptom & N.pharngeal & peritoneum \\
\hline 1.Male & 75 & Liver cirrhosis & Paracentesis & Died day 10 post diagnosis & Yes & Yes & Yes \\
\hline 2.female & 75 & Empyema GB & Lap Chole & Died day 7post D & No & Yes & No \\
\hline 3.Male & 39 & Small bowel perforation & $\begin{array}{l}\text { Resection and } \\
\text { Anastomosis }\end{array}$ & D/C home day 5 & No & Yes & No \\
\hline 4.Male & 32 & Gangrenous appendicitis & Lap Appendix & $\mathrm{D} / \mathrm{C}$ day 4 & No & yes & No \\
\hline 5.Male & 30 & Perforated duodenal ulcer & DU Repair & Died day 7 & Yes & Yes & No \\
\hline 6.Male & 30 & Acute cholecystitis & Lap Cholecystectomy & Day $5 \mathrm{D} / \mathrm{C}$ & Yes & Yes & No \\
\hline 7.Male & 56 & Small bowel ischaemia & Resection\& Anastomosis & Died & Yes & Yes & No \\
\hline 8.Female & 71 & Appendicitis & Lap Appendix & Died D4 & Yes & Yes & No \\
\hline 9.Female & 70 & Sigmoid ischemia & Hartman's Procedure & $\mathrm{D} / \mathrm{C}$ home D5 & Yes & Yes & No \\
\hline 10.Male & 44 & $\begin{array}{l}\text { Liver stab } \\
\text { Haemo Peritoneum }\end{array}$ & Wash out & D3 D/C home & Yes & Yes & No \\
\hline 11.Female & 70 & Haemo Peritonem & Wash out & Died & Yes & Yes & No \\
\hline 12.Female & 70 & Intestinal bleeding & Subtotal Colectomy & Died day 7 & Yes & Yes & Yes \\
\hline 13.Male & 55 & Splenic abscess & Laparotomy\& Drainage & Died day 16 & Yes & Yes & No \\
\hline 14.Male & 78 & $\begin{array}{l}\text { Small bowel obs/omental } \\
\text { band }\end{array}$ & Adhesiolysis & $\mathrm{D} / \mathrm{C}$ home D10 & Yes & Yes & Yes \\
\hline 15.female & 73 & Umbilical hernia & Resection/ Anastomosis & D5 D/c home & Yes & Yes & Yes \\
\hline 16.Female & 80 & Sigmoid Perforation & Hartman's Procedure & Died D2 & Yes & Yes & Yes \\
\hline 17.Female & 71 & End stage renal disease & Peritoneal Dialysis & D/C D8 home & Yes & Yes & Yes \\
\hline 18.Female & 78 & End stage renal disease & Peritoneal Dialysis & $\begin{array}{l}\text { D/C D13 } \\
\text { Home }\end{array}$ & Yes & Yes & Yes \\
\hline
\end{tabular}


The overall mortality rate in patients with Pharyngeal PCR test +ve only and who had surgical intervention is $9 / 18,50 \%$. However, of these 9 patients, 8/9 (88.88\%) patients who died had Respiratory symptom and Pharyngeal PCR test +ve and whereas only $1 / 9$ (11.11\%) patients died who had no Respiratory symptoms but only Pharyngeal PCR test +ve. Which means that among patient who died and who had Respiratory Symptoms and Positive Nasopharyngeal PCR have mortality rate of $8 / 9,88.88 \%$ in this group Table 2. Furthermore, it is observed that among the patients who died 3/9, 33.3\% had Peritoneal fluid positive for PCR test. It is also observed that total of 7 patients had all 3 tests positive (i.e. Respiratory symptoms, Nasopharyngeal PCR \& Peritoneal PCR positive) and out of them 3 died which makes mortality rate in this group 3/7, 42.8\%. Table 2.

\section{Discussion}

The COVID-19 virus enters the cells through the Angiotensin Converting Enzyme-2 receptor, which is not only expressed in pneumocytes (type II alveolar cells), but also expressed in the epithelium of the gastrointestinal tract, from the oesophagus to the colon, notably in ileal and colonic enterocytes also [7]. The cell membrane protein Angiotensin-Converting Enzyme 2 is key for receptor-mediated cell entry of SARS-CoV-2 (Severe Acute Respiratory Syndrome Coronavirus 2) The GI tract can be damaged directly by the COVID-19 infection by the virus entry into the enterocytes or indirectly via the host inflammatory response [8]. The coronavirus through the tissue distribution, causes release of a high number of pro-inflammatory Cytokines which damages the micro vascular system, triggering abnormal activation of the coagulation system, which results generalized small-vessel vasculitis and extensive micro thrombi $[9,10]$. This phenomenon, along with the patient's comorbidities, like hypertension and coronary disease, are linked with high mortality rates and a high risk of coagulation dysfunction.

The ischemia of the whole digestive tract with or without perforation reported may be the outcome of the septic and thromboembolic phenomena, resulted directly or indirectly by the viral infection. $44.4 \%$ (8/18 patients) of the reported cases had varying degrees of bowel Ischemia. Studies have revealed that critically ill patients with COVID-19 are more prone to have a Hypercoagulable state, with the outcome of intravascular coagulation due to local damage $[11,12]$. Table-2 SARS-CoV-2 RNA has been isolated in the blood and faeces of COVID-19 patients $[13,14]$. In our study five out six patients were tested positive when they had rectal swabs. Some authors have conducted studies on peritoneal fluid in COVID-19 positive patients, but without findings of the presence of the virus [15]. Table 2

The real-time reverse transcriptase-polymerase chain reaction used to identify the SARS-CoV-2 RNA genome in peritoneal fluid and nasal swabs. This identifies 3 targets, namely RNA-dependent
RNA polymerase, nucleoprotein (N), and envelope (E) [16]. The peritoneal fluid was detected positive and at levels comparable to the nasal swab and even when retested in 10-fold diluted [16]. This establishes that the viral load in the peritoneal fluid was higher compared to the upper respiratory samples and concluded that the surgical operation was indeed a procedure at risk of infection. Viral isolation, which would have provided stronger evidence of infectivity, could not be performed.

This expressed an important warning about the safety of the operating room staff and demanded an immediate update of the guidelines in order to protect surgical teams. Therefore, all the surgical procedures may risk the potential of aerosolization of the virus and the infection of the members of the surgical teams.

Laparoscopic or open surgical procedures both may result in gas/ vapour forming manoeuvre. Operating devices like electro cautery, coagulation, and cutting devices produce gas and vapour which aerosolize the peritoneal fluid and consequently the virus. Activated Corneybacterium, human papillomavirus, hepatitis B virus, and human immunodeficiency virus have been detected in surgical smoke in the past [17]. Available literature has not shown direct relation between viremia and the severity of clinical picture. But in the presence of mild to moderate symptoms it is less likely to detect a positive viremia than in critically ill patients [18]. If we apply the same concept for the other body fluids, the greater the viremia, the higher the risks. As not much information available about the virus passage to peritoneal cavity and fluids, present data may suggest that potentially all people even those with mild to moderate respiratory symptoms by SARS-CoV-2 could present viral load in peritoneal fluid, thus increasing the exposure and contagion risks for the entire surgical staff. There are inadequate guide lines available to protect the theatre staff from contagion peritoneal fluid as there is not much data supporting potential risks of peritoneal fluids. Few guide lines have recently come up in the literature to help doctors, surgeons and theatre staffs in their daily practice [19].

All the surgical staff should be trained and educated about the potential risks of presence of COVID-19 in the peritoneal fluids and its potential to aerosolize to the environment from the peritoneal fluid in patients with SARS-CoV-2 [16].

\section{Conclusion}

Although there is limited data, but the percentages of detecting the COVID -19 in the peritoneum fluid is considerable. The overall mortality rate in patients with Pharyngeal PCR test +ve and who had surgical intervention is $9 / 18,50 \%$. Patients with Respiratory symptoms are more likely to get peritoneal fluid positive for the disease. Moreover patient who had Respiratory Symptoms and Positive Nasopharyngeal PCR have mortality rate of $8 / 9,88.88 \%$ in this group Moreover it is difficult to comment on the exact mortality and morbidity of patients with COVID-19 in the peritoneal 
fluids as number is small in this study and many other variables can influence the morbidity and mortality in this group. However, this review of the literature is very informative for surgeons and other theatre staff for increasing their level of awareness and protection especially in emergency surgical setting.

\section{References:}

1. Poggliali E, Ramos PM, Bastoni D, Vercelli a, Magnacavallo A. Abdominal pain: a real challenge in novel COVID-19 infection. Eur J Case Rep Intern Med. 2020; 7: 001632.

2. Coccolini F, Perrone G, Chiarugi M. Surgery in COVID-19 patients: operational directives. World J Emerg Surg. 2020 ; 15: 25.

3. Mi B, Chen L, Xiong Y. Characteristics and Early Prognosis of COVID-19 Infection in Fracture Patients. J. Bone Joint Surg Am. 2020; 102: 750-8.

4. Kokkinakis I, Selby K, Favrat B. Covid-19 diagnosis: clinical recommendations and performance of nasopharyngeal swab-PCR. Rev Med Suisse. 2020: 16: 699-701.

5. Winichakoon P, Chaiwarith R, Liwsrisakun C. Negative Nasopharyngeal and Oropharyngeal Swab Does. Not Rule Out COVID-19. Q. J Clin Microbiol. 2020; 58: 00297-20.

6. Rimini E, Atzori G, Viotti A. COVID-19 in the peritoneal fluid: does this evidence oblige to introduce new rules? Presentation of a Case Report. 2020.

7. Wong SH, Lui RN, Sung JJ. Covid-19 and the digestive system. J Gastroenterol Hepatol. 2020; 35: 744-8.

8. Patel KP, Patel PA, Vunnam RR. Gastrointestinal, hepatobiliary, and pancreatic manifestations of COVID-19. J Clin Virol. 2020; 128: 104386.

9. Chen N, Zhou M, Dong X, Qu J, Gong F, Han Y, et al. Epidemiological and clinical characteristics of 99 cases of 2019 novel coronavirus pneumonia in Wuhan, China: a descriptive study. Lancet. 2020; 395: 507-13.

10. Song Y, Liu P, Shi XL, Chu YL, Zhang J, Xia J, et al. SARS-CoV-2 induced diarrhoea as onset symptom in patient with COVID-19. Gut. 2020; 69: 1143-44.

11. Wang W, Gao R, Zheng Y, Jiang L. COVID-19 with spontaneous pneumothorax, pneumomediastinum and subcutaneous emphysem. J Travel Med. 2020; 27: 062.

12. Zhou B, She J, Wang Y, Ma X. Venous thrombosis and arteriosclerosis obliterans of lower extremities in a very severe patient with 2019 novel coronavirus disease: a case report. J Thromb Thrombolysis. 2020; 50: 229-32.

13. Mallick R, Odejinmi F, Clark TJ. Covid 19 pandemic and gynaecological laparoscopic surgery: knowns and unknowns. Facts Views Vis Obgyn. 2020; 12: 3-7.

14. Wang W, Xu Y, Gao R. Detection of SARS-CoV-2 in different types of clinical specimens. JAMA. 2020. 32: 1843-44.

15. Emile SH. Should we continue usinglaparoscopy amid the COVID-19 pandemic? Br J Surg. 2020; 107: 240-1.
16. Coccolini F, Tartaglia D, Puglisi A. SARS-CoV-2 Is Present in Peritoneal Fluid in COVID-19 Patients, Ann Surg. 2020; 272: 240-2.

17. Mallick R, Odejinmi F, Clark TJ. Covid 19 pandemic and gynaecological laparoscopic surgery: knowns and unknowns. Facts Views Vis Obgyn. 2020; 12: 3-7.

18. Chen X, Zhao B, Qu Y. Detectable serum SARS-CoV-2 viral load (RNAaemia) is closely correlated with drastically elevated interleukin 6 (IL-6) level in critically ill COVID-19 patients. Clin Infect Dis. 2020; 71: 1937-42.

19. Coccolini F, Perrone G, Chiarugi M. Surgery in COVID-19 patients: operative indications. World J Emerg Surg. 2020; 15: 25. 